\title{
The Adrenal Gland: Central Relay in Health and Disease
}

\author{
Authors \\ Martin Reincke', Felix Beuschlein ${ }^{1,2}$, Stefan Bornstein ${ }^{3}$, Graeme Eisenhofer ${ }^{3,4}$, Martin Fassnacht ${ }^{5}$, Nicole Reisch', \\ Tracy Ann Williams1, 6
}

\section{Affiliations}

1 Medizinische Klinik und Poliklinik IV, Klinikum der Universität, Ludwig-Maximilians-Universität München, Germany

2 Klinik für Endokrinologie, Diabetologie und Klinische Ernährung, Universitäts-Spital Zürich, Zürich, Switzerland

3 Department of Medicine III, University Hospital Carl Gustav Carus, Dresden, Germany

4 Institute of Clinical Chemistry and Laboratory Medicine, University Hospital Carl Gustav Carus, Dresden, Germany

5 Department of Internal Medicine I, Division of Endocrinology and Diabetes, University Hospital, University of Würzburg, Würzburg, Germany

6 Division of Internal Medicine and Hypertension, Department of Medical Sciences, University of Turin, Turin, Italy

\section{Key words}

Addison disease, congenital adrenal hyperplasia, Cushing's syndrome, hypercortisolism, primary aldosteronism, adrenocortical carcinoma, pheochromocytoma, paraganglioma received 25.09.2018

revised 25.09.2018

accepted 28.09.2018

\author{
Bibliography \\ DOI https://doi.org/10.1055/a-0752-4176 \\ Exp Clin Endocrinol Diabetes 2019; 127: 81-83 \\ (C) J. A. Barth Verlag in Georg Thieme Verlag KG Stuttgart . \\ New York \\ ISSN 0947-7349

\section{Correspondence} \\ Martin Reincke, MD \\ Medizinische Klinik und Poliklinik IV \\ Klinikum der Universität München \\ LMU München \\ Ziemssenstr. 1, 80336 München \\ Germany \\ Tel.: + 49/89/44005 2100, Fax: + 49/89/44005 4428 \\ martin.reincke@med.uni-muenchen.de
}

\section{Introduction}

Diseases of the adrenal gland are as important for the general practitioner as for the endocrine specialist. The high prevalence of some adrenal endocrinopathies, such as adrenal incidentalomas (1-2\% of the population) and primary aldosteronism (6\% of hypertensives), which affect millions of patients, makes adrenal diseases a relevant health issue. The high morbidity and mortality of some of the rarer adrenal diseases, i. e., Addison's disease and Cushing's syndrome ( $\vee$ Table 1 ), make early detection and appropriate treatment such a challenge for the health care system.

Progress in genomics, transcriptomics and steroidobolomics has advanced our understanding of adrenal pathologies including primary aldosteronism [1], Cushing's syndrome [2], adrenocortical carcinoma [3], and pheochromocytoma [4]. Recent progress has been made in the pathophysiology of many rare adrenal diseases. Foremost has been the identification of somatic driver mutations in adrenal cortical neoplasms responsible for the characteristic endocrine autonomy and limited proliferative activity of these endocrine tumors [1]. The rich genetic background of neoplasms derived from adrenal and extra-adrenal chromaffin cells is well established with over 16 germline mutation identified to date, many of these and other (HIF2a, IDH1 \& 2, HRAS) also contributing via somatic driver events [4]. It is within this horizon that adrenal diseases have become a general topic in research and in clinics.

\section{The Adrenal Cortex Conference in Munich 2018}

In June 2018, we had the privilege to organize the $18^{\text {th }}$ Adrenal Cortex Conference in Munich. Since 1984 the Conference on the Adrenal Cortex has provided an exciting combination of science and resources for basic and clinical scientists. The 2018 conference continued the tradition of including renowned speakers covering the latest research on adrenal development, hormone signaling, steroidogenesis, adrenal insufficiency, primary aldosteronism, Cushing's syndrome and adrenal cancer. As in previous meetings, the Keith L. Parker Memorial Lecture was awarded to an international leader for his contribution to adrenal research. This year's laureate was William E. Rainey, the Jerome W. Conn Professor at the University of Michigan, Ann Arbor, USA, who presented a lecture on his most recent research on the molecular pathophysiology of primary aldosteronism. Two hundred scientists from around the globe participated in this prime event of adrenal research giving the meeting a truly international flavor. More than 100 investigators including many students and young post-docs presented their research as posters or oral communications. 
- Table 1 Incidence and prevalence of adrenal diseases in Europe.

\begin{tabular}{|c|c|c|c|c|}
\hline & Annual incidence & Prevalence & Morbidity & Mortality \\
\hline $\begin{array}{l}\text { Congenital adrenal } \\
\text { hyperplasia }\end{array}$ & $1: 10.000-1: 15.000$ & & $\begin{array}{l}5.8 \text { crises per } 100 \\
\text { patient-years; } \\
\text { salt wasting: } \\
8.8 \text {; simple } \\
\text { virilising: } 2.5\end{array}$ & $\begin{array}{l}\text { The HR of dying } 2.3(95 \% \mathrm{Cl}, 1.2-4.3) \text { in } \mathrm{CAH} \text { males } \\
\text { and } 3.5(95 \% \mathrm{Cl}, 2.0-6.0) \text { in CAH females compared } \\
\text { with controls }\end{array}$ \\
\hline Addison's disease & $4.5 / 1000.000$ & $82-144 / 1000.000$ & $\begin{array}{l}6-8 \text { adrenal crisis/ } 100 \\
\text { patients/year }\end{array}$ & 0.5 deaths $/ 100$ patient-years from adrenal crisis \\
\hline $\begin{array}{l}\text { Primary } \\
\text { aldosteronism }\end{array}$ & n.k. & $\begin{array}{l}4-6 \% \text { of hypertensive } \\
\text { population }\end{array}$ & $\begin{array}{l}\text { OR for stroke: } 4.2 ; \text { OR } \\
\text { for MI: } 6.5 ; \\
\text { OR for AF: } 12.1 \\
\text { compared to EH }\end{array}$ & 2 times increased for treated PA (IAH) \\
\hline Cushing disease & $1-3 / 1000.000$ & $66 / 1000.000$ & & SMR for all-cause mortality in treated CD: 1.61 \\
\hline $\begin{array}{l}\text { Incidentally detected } \\
\text { adrenal mass }\end{array}$ & n.k. & $\begin{array}{l}1-2 \% \text { of general } \\
\text { population }\end{array}$ & n.k. & n.k. \\
\hline $\begin{array}{l}\text { Adrenocortical } \\
\text { carcinoma }\end{array}$ & $0.7-2.0 / 1.000 .000$ & & & $\begin{array}{l}\text { Median survival: } 3-4 \text { years, } 5 \text {-year survival } 60-80 \% \text { for } \\
\text { localized tumors, and } 10-20 \% \text { for metastatic disease }\end{array}$ \\
\hline
\end{tabular}

We acknowledge the generous support of the Deutsche Forschungsgemeinschaft, which enabled us to invite many of the internationally leading researchers in the field. Furthermore, the present March volume of Experimental and Clinical Endocrinology and Diabetes is entirely dedicated to reviews covering advances in the field of primary aldosteronism. They are written by experts in their respective fields and include twelve invited articles summarizing main topics covered at the symposium.

Primary aldosteronism (PA) has been identified as the leading endocrine cause of hypertension in recent years. Although still utterly underdiagnosed in clinical practice recent data point to a higher detection rate in some countries. PA is easily picked up if screened by the aldosterone-to-renin ratio. However, there are many factors influencing sensitivity and specificity of the ratio, an area explored by the review of Schilbach, et al. [5]. Perez-Rivas et al. [6] cover in their review on familial hyperaldosteronism the most recent genetic findings currently leading to a potential reclassification. Although there has been a debate about the true prevalence, with estimates up to $6 \%$ in systematic screening approaches [7], genetically confirmed familial hyperaldosteronism remains a quite rare entity affecting less than $1 \%$ of diagnosed cases of primary aldosteronism. Usually, affected patients present early in infancy and have a severe course of the disease. Yang et al. [8] provide an analysis of the outcome of adrenalectomy in unilateral primary aldosteronism. Based on a recently established expert consensus of 31 specialists, assessment of outcome has been standardized allowing improved comparison between cohorts of different geographic and genetic backgrounds [9]. However, this analysis also demonstrated that a certain percentage of patients have in biochemical terms persistent hyperaldosteronism, and the underlying pathophysiology is discussed in this review.

Two manuscripts review the recent advances in the treatment of malignant adrenal diseases, namely adrenocortical carcinoma (ACC) and malignant pheochromocytoma/paraganglioma (PPGL). A major breakthrough in treatment of adrenocortical carcinoma has been the FIRMACT trial published in 2012 [10] which reported results of a randomized trial comparing 2 chemotherapeutic regi- mens in stage IV ACC. As a result of this trial, multiple second and third line therapies have been evaluated [11] which are reported in the review article by Megerle et al. [12]. Approximately $10 \%$ of all PPGL are malignant, and treatment options in metastasized disease stages include radioactive treatment options (MIBG, somatostatin receptor based approaches), classical chemotherapy protocols and targeted treatment approaches. Nölting et al. [13] provide a comprehensive overview of the most recent advances in the field, including promising pre-clinical data not yet used in clinical practice.

Erlic and Beuschlein [14] summarize the metabolic alterations found in PPGL, including impaired glucose homeostasis and lipolysis activation, changes in body weight, fat mass and distribution. Schreiner et al. cover the highly relevant topic of perioperative management of adrenal tumors [15]. In clinical practice this area is associated with serious morbidity and mortality which can be avoided by appropriate management.

Cushing disease (CD), caused by corticotroph adenomas of the pituitary, is a rare devastating disease with high clinical burden. Remission by transsphenoidal adenomectomy is achieved in 78\% [16], but often metabolic, cardiovascular, musculoskeletal and psychiatric comorbidities persist after long-term biochemical control. These chronically ill patients show an increased mortality despite disease remission. According to the review by Stalla et al. [17], comorbidities should be treated aggressively and life-long surveillance is necessary to identify tumor recurrence at an early stage. Kamilaris et al. [18] give an excellent overview of genetics and clinics of primary pigmented nodular adrenal disease, a rare cause of adrenal Cushing's syndrome, often associated with additional syndromatic features.

This special issue also highlights the importance of non-tumorous adrenal diseases with high morbidity, such as Addison's disease and congenital adrenal hyperplasia. In a timely review, Barthel et al. [19] reflect upon current treatment standards in Addison's disease and improvements in long-term care. Reisch [20] summarizes the long-term sequelae observed in patients with congenital adrenal hyperplasia. There is a shift from the pediatric focus on management of adrenal crisis and growth to adult problems, namely reproduction and prevention of longterm cardiovascular and metabolic consequences of the disease. 
The final manuscript by Di Dalmazi [21] addresses recent progress in adrenal incidentalomas, a topic which has been covered by a European guideline in 2016 [3]. In clinical practice these guidelines have proven to be very helpful. However, as in other areas of adrenal research, many open questions remain and have to be addressed by future studies.

It is within this context that the recently established clinical research center (CRC), "The adrenal gland: central relay in health and disease" [22], is well suited to approach clinical issues and basic research questions. The Deutsche Forschungsgemeinschaft approved funding for this program with 13 mio $€$ from 2017 to 2021, with the option of a further extension until 2029. The 17 research projects and two central support projects at the University Hospitals of Dresden, Munich and Würzburg cover a broad spectrum ranging from sepsis research to Cushing's syndrome, and adrenal gland organ replacement to rodent models of autoimmune adrenal disease. Several of its principal investigators of the CRC are authors of reviews of this special issue. Other authors are close collaborators of the CRC scientists, reflecting its international outreach. This special issue of Experimental and Clinical Endocrinology and Diabetes provides the interested reader with an opportunity to understand where we are, and where our research has to go until the next Adrenal Cortex Conference in 2020.

\section{Funding}

We acknowledge the generous support of the Deutsche Forschungsgemeinschaft (CRC/TRR 205/1 "The adrenal gland: Central relay in health and disease" as well as for the Adrenal Cortex Conference; FA 466/9-1). Additional grant support of the authors of this editorial are: the Deutsche Forschungsgemeinschaft (Heisenberg Professorship, project number 325768017 to N.R.), the Else KrönerFresenius Stiftung (German Conn's Registry-Else-Kröner Hyperaldosteronism Registry; 2013_A182 and 2015_A171) to M.R., the Deutsche Forschungsgemeinschaft to M.R. (RE 752/20-1), to F.B. (BE2177/13-1), to M.F. (FA 466/4-2; FA 466/8-1); the European Research Council (grant number 694913 [PAPA] to M.R.),

\section{Conflict of Interest}

No conflict of interest has been declared by the authors.

\section{References}

[1] Prada ETA, Burrello J, Reincke M et al. Old and New Concepts in the Molecular Pathogenesis of Primary Aldosteronism. Hypertension. 2017; 70: 875-881. doi:10.1161/HYPERTENSIONAHA.117.10111.

[2] Albani A, Theodoropoulou M, Reincke M. Genetics of Cushing's disease. Clin Endocrinol (Oxf) 2018; 88: 3-12. doi:10.1111/cen.13457.

[3] Fassnacht M, Arlt W, Bancos I et al. Management of adrenal incidentalomas: European society of endocrinology clinical practice guideline in collaboration with the European network for the study of adrenal tumors. Eur J Endocrinol 2016; 175: G1-G34. doi:10.1530/EJE-16-0467.
[4] Crona J, Taïeb D, Pacak K. New Perspectives on Pheochromocytoma and Paraganglioma: Toward a molecular classification. Endocr Rev 2017; 38: 489-515. doi:10.1210/er.2017-00062.

[5] Schilbach K, Junnila R, Bidlingmaier $M$. The aldosterone to renin ratio as screening tool in primary aldosteronism. Exp Clin Endocrinol Diabetes 2019; 127: 84-92

[6] Pérez-Rivas LG, Williams T, Reincke M. Inherited forms of primary hyperaldosteronism: new genes, new phenotypes and proposition of a new classification. Exp Clin Endocrinol Diabetes 2018; 12: 93-99

[7] Mulatero P, Tizzani D, Viola A et al. Prevalence and characteristics of familial hyperaldosteronism: The PATOGEN study (Primary Aldosteronism in TOrino-GENetic forms). Hypertension 2011; 58: 797-803. doi:10.1161/HYPERTENSIONAHA.111.175083.

[8] Yang Y, Reincke M, Williams T. Treatment of unilateral PA by adrenalectomy: Potential reasons for incomplete biochemical cure. Exp Clin Endocrinol Diabetes 2019; 127: 100-108

[9] Williams TA, Lenders JWM, Mulatero P et al. Outcomes after adrenalectomy for unilateral primary aldosteronism: An international consensus on outcome measures and analysis of remission rates in an international cohort. Lancet Diabetes Endocrinol 2017; 5: 689-699. doi:10.1016/S2213-8587(17)30135-3.

[10] Fassnacht M, Terzolo M, Allolio B et al. Combination chemotherapy in advanced adrenocortical carcinoma. N Engl J Med 2012; 366: 2189-2197. doi:10.1056/NEJMoa1200966.

[11] Kroiss M, Deutschbein T, Schlötelburg W et al. Treatment of Refractory Adrenocortical Carcinoma with Thalidomide: Analysis of 27 Patients from the European Network for the Study of Adrenal Tumours Registry. Exp Clin Endocrinol Diabetes 2018 DOI 10.1055/a-0747-5571.

[12] Megerle F, Kroiss M, Hahner S, Fassnacht M. Advanced Adrenocortical Carcinoma - What to do when First-Line Therapy Fails? Exp Clin Endocrinol Diabetes. 2019; 127: 109-116

[13] Nölting S, Grossman AB, Pacak K. Metastatic Phaeochromocytoma: Spinning towards more promising treatment options. Exp Clin Endocrinol Diabetes 2019; 127: 117-128

[14] Erlic Z, Beuschlein F. Metabolic alterations in patients with pheochromocytoma. Exp Clin Endocrinol Diabetes 2019; 127: 129-136

[15] Schreiner F, Anand G, Beuschlein F. Perioperative management of endocrine active adrenal tumors. Exp Clin Endocrinol Diabetes 2019; 127: 137-146

[16] Petersenn S, Beckers A, Ferone D et al. Therapy of endocrine disease: outcomes in patients with Cushing's disease undergoing transsphenoidal surgery: Systematic review assessing criteria used to define remission and recurrence. Eur J Endocrinol. 2015; 172: R227-R239. doi:10.1530/EJE-14-0883.

[17] Stalla GK, Ciato D, Dimopoulou C. Cushing's disease. Exp Clin Endocrinol Diabetes 2019; 127: 147-155

[18] Kamilaris CDC, Faucz FR, Voutetakis A, Stratakis CA et al. Carney complex. Exp Clin Endocrinol Diabetes 2019; 127: 156-164

[19] Barthel A, Benker G, Berens K et al. An update on Addison's disease. Exp Clin Endocrinol Diabetes 2019; 127: 165-170

[20] Reisch N. Review of health problems in adult patients with congenital adrenal hyperplasia. Exp Clin Endocrinol Diabetes 2019; 127: 171-177

[21] Di Dalmazi G. Adrenal incidentaloma: picking out the high-risk patients. Exp Clin Endocrinol Diabetes 2019; 127: 178-184

[22] http://www.dfg.de/gefoerderte_projekte/programme_und_projekte/ listen/projektdetails/index.jsp?id = 314061271 